\title{
This Is Our Music?: Tradition, community and musical identity in contemporary British jazz
}

\section{Mike Fletcher}

As we reach the middle of the second decade of the twenty-first century we are also drawing close to the centenary of jazz as a distinct genre of music. Of course, attempting to pinpoint an exact date would be a futile endeavour but nevertheless, what is clear is that jazz has evolved at a remarkable rate during its relatively short lifespan. This evolution, which encompassed many stylistic changes and innovations, was aided in no small part by the rapid technological advances of the twentieth century. Thus, what was initially a relatively localised music has been transformed into a truly global art form. Within a few short decades of the birth of the music, records, radio broadcasts and globe-trotting American jazz performers had already spread the music to a listening audience worldwide, and it was not long after this that musicians began to make attempts to 'adapt jazz to the social circumstances and musical standards with which they were more familiar'. ${ }^{1}$ In the intervening decades, subsequent generations of indigenous musicians have formed national lineages that run parallel to those in America, and variations in cultural and social conditions have resulted in a diverse range of performance practices, all of which today fall under the broad heading of jazz. As a result, contemporary musicians and scholars alike are faced with increasing considerations of ownership and authenticity, ultimately being compelled to question whether the term jazz is still applicable to forms of music making that have grown so far away from their historical and geographic origins.

In this chapter I focus specifically on jazz and improvised music in twenty-first century Britain. I consider the extent to which musicians active in this area identify with the historical origins of jazz, the way they understand their work in relation to divergent musical 
lineages, and the practical implications of these questions in terms of their musical activity. My motivation for tackling the subject is borne of the fact that I am both a practitioner and a researcher, and is also due in no small part to my cultural background as a white, British jazz musician. Therefore my interest is practical as well as theoretical, and consequently this study can be seen as the evolution of a line of questioning that pertains to my own creative practice.

My professional involvement with jazz in the UK has afforded me the opportunity to not only play with some of the most creative musicians currently practicing, but also to spend many hours talking to them. Therefore, when I was invited to contribute to this collection, I identified an opportunity to formalise these conversations and present them to a wider audience. In order to do this, I conducted interviews with six musicians whom I would count in general terms as being among my 'peers' - that is to say, whose creative aesthetic leads them to question the relevance of traditional forms of music-making, and whose musical activity has predominantly occurred since the turn of the century. Although to some extent I have tried to include performers of instruments from different stylistic areas and to remain unbiased in terms of race and gender, the group is in no way fully representative of any particular demographic and, rather than being the result of a scientifically sound selection process, is as much dependent on the availability and willingness of the subjects to participate in my study. As a result, what follows does not pretend to offer a comprehensive survey of a musical community as a whole, but rather a brief introduction to the diverse range of opinion and understanding among today's practicing jazz musicians.

It should also be noted that as a consequence of my connection with this relatively specialist area of music, I have a degree of association with each of my interview subjects. In the cases where we have never actually shared a stage, we have at least one performance colleague in common. I acknowledge this fact would have a bearing on my impartiality were I writing in a purely critical capacity. However, I believe that for this type of work my position as practitioner/researcher affords me a level of understanding and empathy that is 
actually of significant benefit. Therefore, in addition to the interview material - and where I feel it is relevant - I contribute thoughts from my own perspective as a performing musician. Throughout the course of the article I contextualise this primary source material from the point of view of a researcher, with the objective of giving an overview of the state of thinking among those who are currently engaged in re-shaping the jazz landscape in Britain.

A final point to address before proceeding is that this type of ethnographic approach to jazz study is not without significant precedent. Berliner and Monson are but two key examples that deal with the practice in the context of the US and which have provided me with an invaluable source of inspiration for my own investigation. ${ }^{2}$ In terms of jazz in Britain, Horne gives an insight via a series of biographically oriented interviews and the recently published collection Black British Jazz, as the title implies, is concerned with the issues surrounding race and jazz in Britain. ${ }^{3}$ In terms of texts by practicing musicians, Carr's book Music Outside is one of the seminal works, addressing as it does the life and work of a selection of his contemporaries. ${ }^{4}$ In this sense, my study can be seen as revisiting the ground covered by Carr by addressing similar issues four decades on, considering their continued relevance and contemplating the factors involved in being a creative jazz musician in twentyfirst century Britain.

\section{Background}

In order to contextualise the questions that I will be posing, I will first offer a short autobiographical summary of my introduction to jazz. I was born in Birmingham, UK, in the early 1980 s and raised in what, in terms of income and social position, was an average family. What is of more relevance here is that my father is an avid jazz fan and amateur saxophonist. As a result of this, I grew up surrounded by jazz music on record and, to a lesser extent, in live performance. Although I did not begin to learn the saxophone - and 
consequently to engage with jazz as a performer - until I was in my early teens, I quite quickly came to recognise and identify by ear the characteristic sounds of certain key musicians on the records I heard around the house (Louis Armstrong, Billie Holiday and Lester Young were among my early favourites). One effect of this regular and extended exposure to jazz during early childhood and adolescence was to give me a strong aural affinity with the idiom. Not only did I become familiar with many of the Broadway songs, blues and other such pieces that comprise the jazz canon, I also developed a subconscious ear for the inflections, melodic patterns and other idiomatic aspects that make up the 'language' of jazz.

Therefore, in purely objective terms, I feel myself to have a relatively strong foundation in jazz. At that time, I had no intention of making jazz my profession, and I was absorbing what I heard without questioning its meaning or origin. Jazz was, to my childish ears, just another series of sounds to be processed and assimilated along with all the others that I encountered during daily life. In this way, I would argue that I learned to understand jazz in much the same way as I learned to understand the English language, via prolonged and regular exposure to it in my home environment. This familiarity with the idiom was to be of great benefit to me when, in my early teens, I decided to take up the saxophone. My inner ear already heard many of the sounds I wanted to produce, so when it came to learning melodies and transcriptions of improvised solos, my task was made much easier. All I had to do was acquire the instrumental facility to reproduce what was in my head. In this way, my path into being a jazz performer was quite intuitive.

However, as time went on, I became increasingly aware that, were I to continue my involvement in jazz as a professional performer, I would start to find myself faced with certain questions. After spending several years performing with youth jazz orchestras and completing my undergraduate studies in jazz, I began to detect within myself a certain sense of dissatisfaction - or at least uneasiness - with respect to the way I engaged with jazz. In 
essence, I came to realise that the music I had grown up with was the product of a culture and historical time period with which I had little connection in real terms. My father's listening tastes are essentially quite conservative, so the music I heard as a child was mainstream jazz of the 1940s and 1950s. Once I began my formal studies, much of the theory I was taught was based on the performance practice of the same musicians that I had listened to at home. At the same time, reading around the subject and talking the musicians I met made me increasingly aware of the significance of cultural and racial implications inherent in jazz and that, instead of being something to read about in the history books, these issues would directly impact on me and my music. Therefore, I began to question to what extent this musical language that I had unwittingly acquired was relevant to me. To put it in simple terms, I felt that the language I had learned to speak was of a different time and place, and as a newly 'qualified' jazz musician ready to make my mark on the twenty-first century jazz scene - I started to wonder how to speak this language in a way that reflected the time and place that I lived in.

\section{Initial questions}

As I have briefly outlined, my journey into jazz has been not only one of creative selfdiscovery, but also one of philosophical questioning and recent years, my conversations with my peers have shown me that such questions are an integral part of life as a twenty-first century performer. In the process of researching a different piece I came across the following series of questions posed by Alan Trachtenberg:

What does the blues mean today, as historical heritage, as performative experience, as cultural event? By whom is this meaning determined? And who deserves the authority to say so? To whom does this heritage belong? How are heritages formed? How do they live in the continuing process of culture, 
processes that are increasingly recognised as paradoxical and challenging, made up of overlapping and still conflicting cultural interests? ${ }^{5}$

Although ostensibly relating to delta blues, in the context of my questioning my own relationship to the historical tradition of American jazz, Trachtenberg's questions seem to hold a particular resonance. Therefore, based on the ideas of heritage, culture, history and ownership, I undertook a series of interviews with certain colleagues to explore how they relate to these questions.

\section{The 'American question'}

The first issue I will address is the relationship between jazz and the USA. A popular conception is that jazz is synonymous with a particular facet of American culture and that, as a result, '...only those who have internalised the culture and way of life of AfricanAmericans can become jazz musicians. ${ }^{6}$ A statement such as this raises many important questions for a non-American jazz musician such as myself. Does Marsalis have the authority to make such a judgement? If he is correct, how am I to understand my musical activity? If he is not, what has led him to believe that he is? Although I do not pretend to have definitive answers to any of these questions, my personal opinion is that an awareness of the various factors that contribute to the debate is essential for the contemporary jazz musician, and that understanding the way British musicians relate to these issues can make a valuable contribution to the current discourse on jazz in the UK.

In 2001 - and thus neatly coinciding with the beginning of my designated era of study - Ken Burns' documentary Jazz was aired on American television. Despite being a huge commercial success, it was the subject of much criticism from within the jazz world, most of which fell into one of two camps. Many critics objected to its apparent neo-conservative reading of jazz, citing its emphasis on first half of the twentieth century at the expense of developments after the 1960s. However, as Atkins points out, 'few of Burns' American 
critics objected to the filmmaker's decision to omit virtually all mention of relevant developments in other countries. ${ }^{97}$ Therefore, the second criticism was more prevalent among European commentators centred on the fact that the series failed to acknowledge, if not the existence, then at least the influence or legitimacy of jazz beyond American borders.

The artistic director for Burns' series was Wynton Marsalis who, as a result of his involvement with Jazz and on-going tenure as director of Jazz at Lincoln Center (JALC), is a figure that is often considered central this particular debate. The finer details of how and why Marsalis has become such a visible and controversial figure are understandably too complex to be fully explored here, suffice it to say that much heated discourse surrounds the subject. ${ }^{8}$ What is more important in this context is that Marsalis - in addition to writers Stanley Crouch and Albert Murray - are commonly cited as the figureheads of a neo-classical, proAmerican vision of jazz whose parameters are extremely narrow in terms of both musical innovation and cultural diversity. While it would be hard to argue that this triumvirate is entirely to blame for this phenomenon, they can be seen as representing a point of view that, in recent times, has become so ubiquitous that 'we have become [...] used to thinking of jazz as a quintessentially American form, one that cannot be separated from the ideological claims that Americans make about themselves. ${ }^{9}$ Whether or not as a direct result of the increasingly nationalistic emphasis on American jazz, there has been something of a backlash from certain quarters. Not surprisingly, many of the prominent voices belong to European commentators. Once again, I will avoid becoming mired in the complexities of these arguments, although acknowledging and contextualising them to a certain extent will be of value to my later discussion. The main thrust of the pro-European camp is that America has become too preoccupied with preserving the tradition at the expense of innovation, and that European jazz is now the vanguard of the music. ${ }^{10}$

My own stance is that of a European jazz musician whose listening background - and therefore also a degree of historical and stylistic allegiance - is indebted to the American jazz 
tradition. As such, I find myself somewhat caught between these two camps. Although I live and work almost exclusively in Europe, I feel like my music is very much a product of that history. However, despite feeling conflicted by the increasingly polemical discourse among some commentators, I am aware of a relative lack of evidence for such a divide 'on the ground'. As a performer I have worked with both British and American musicians in varying combinations, and rarely do I experience the sort of divisions or incompatibility that the rhetoric might suggest.

However, that the debate exists at all provides compelling evidence of certain complications, so in order to better understand what it means to be a non-American jazz musician, it is first necessary to consider where such doubts might have originated. Therefore, I will now begin to address these issues by contemplating certain aspects of the historical relationship between American and British jazz. It is in the following section that I will begin to introduce thoughts and comments from my six interviewees so as to offer an insight into how these musicians understand the issues.

\section{History}

In the UK, the issue certainly has a strong precedent. Ian Carr, writing in 1973, commented on the 'traditional and romantic view' that grants an 'innate and magical superiority' to American nationals. ${ }^{11}$ This indicates that, by the early 1970s, it was already well established as a way of thinking and so it is safe to assume the origin goes back yet further. Alto saxophonist Peter King, when discussing his formative years on the London scene, offered an insight into this phenomenon in an earlier era:

Before the Americans came over, we didn't really know how good we were. And it wasn't til they came over and told us how good we were that we started to realise that maybe we weren't bad after all. ${ }^{12}$ 
Here King is describing the situation in the middle to late $1950 \mathrm{~s}-$ a period when the jazz scene in Britain was still relatively young. What is clear from King's statement is, at that point in time, many British musicians felt that they needed their credentials to be validated by a group they perceived as having the authority to do so. It would appear that King's generation did not have a strong sense of entitlement or ownership of the music they performed. If this was the case, what could have caused them to think like this?

In order to understand King's words, it is important to contextualise them and to understand that the era in which these musicians were living and working would have had a significant impact on the way they thought. In the 1950s, the major stylistic innovations in jazz were still essentially being made in the US by American musicians. In addition to this, many of the early generation of jazz musicians were still alive and living there. To understand the potential implications of this, it is necessary to account for the importance of master/disciple tradition in jazz, which Nicholas Payton refers to in an interview with Ethan Iverson and which Soweto Kinch acknowledged when I spoke to him:

Payton: It used to be that the true masters decided who was next. There was a clear lineage in place: whom begat whom [sic.]. ${ }^{13}$

Kinch: Look at the stories of John Coltrane or Charlie Parker, and especially like Diz, that they spent time around Louis Armstrong's house. So the elders, the icons directly above them were accessible. You see photographs of Johnny Hodges playing and there's younger cats of the bebop era looking on in astonishment. $^{14}$

What these two quotes reveal is the importance of understanding jazz in terms of an oral tradition rather than simply as a stylistic concept. Kinch again:

I feel like jazz is an identifiable tradition, not just a genre, and I think there are crucial reasons why there's an important distinction between the two [...] As a 
tradition, I've been able to see that you learn the language while you're becoming steeped in it. ${ }^{15}$

The key here is becoming 'steeped' in jazz. The well-known adage tells us that the best way to learn a foreign language is to spend time surrounded by native speakers, and the same is essentially true of a social form of music making. A community of active jazz musicians - as well as providing colleagues with whom to perform - also functions as a 'large educational system'. ${ }^{16}$ The first generation of modern jazz musicians in London - of which King was a member - was a network of players that had access to performance venues, and so would not have lacked the opportunity to play music on a regular basis. In this sense, they can be seen as having been part of an active community. However, what they lacked was the lineage of 'true masters' that would have provided the education and guidance required by the younger musicians, and furthermore, a direct link to a historical tradition. It is therefore not so surprising to find that they looked to American musicians to fill the gap left by their own missing elder statesmen. This feeling was likely to have been further exacerbated by the Musician's Union ban, which had been in place since 1935 and prevented touring American bands from visiting the UK. By the middle of the 1950s this ban was only just starting to be relaxed and, as a result, the musicians in Britain would have had extremely few opportunities for interaction with their American counterparts. Because of this, their access to jazz was for the most part limited to recordings, and so, for want of direct contact with the 'source' of the music, doubts about authenticity and ownership would have been entirely understandable.

However, it should be noted that not every musician active during this period felt the same. Joe Harriott, a West Indian-born alto saxophonist and contemporary of King, was much more resistant to the American-centric jazz ideal:

I also have a pet hate, that one couldn't think for oneself unless one emigrated to a place like the United States. Whether one goes to the States or lives in the 
jungle, one can think [...] There shouldn't be one place leading the thinking public or the musicians or aspiring artists, because throughout history and arts there's enough proof that [inventive] people came from all over the place. Unfortunately I find, I hope I'm wrong about this, that jazz musicians, American and otherwise, seem to think that one could only be a good musician by being in the United States. ${ }^{17}$

Toynbee uses this quote in a paper on black British jazz, and goes on to suggest that Harriott's defiance might come as a result of his cultural background, asserting that 'African diasporic heritage provided the conditions for a certain state of cultural independence. ${ }^{18}$ Kinch, who, like Harriott, is an alto saxophonist of West Indian heritage, seems to support the possibility that a sense of inferiority might be borne of an inherently British propensity towards classification and categorization:

I think most of those questions come from the white, British, middle class world itself. This whole thing - I have it inherent in me as well. Going to Cuba and expecting salsa to be a particular sort of thing comes from a culture of 'Well, you can't possibly know about that because you don't know which fork to use'. ${ }^{19}$

While I accept that this would surely have had some bearing on the situation, what is interesting to me about Harriott's comments is that he doesn't refer directly to race or nationality as being the source of the problem. ${ }^{20}$ Instead, he seems to identify the issue as being more one of geographical location. Here I return to look at Carr's earlier comments in more detail:

It occurred to me...that Americans had been superior in the music, not because they had some innate and magical superiority (the traditional, romantic view), but rather because the cultural and economic climate made it possible to keep together regularly working units. ${ }^{21}$ 
Although they oppose each other regarding the veracity of the claim (the reasons for which I will not pursue here), what both Harriott and Carr reveal is that one facet of the 'American question' pertains to geographical location. Kit Downes acknowledges this as something that is still relevant today:

The way the live scene is here [in Britain] isn't set up to support that either. Even getting asked to be in Clark [Tracey]'s band, I was quite excited because it was playing with an older guy who had a connection to Stan Tracey. But even then we wouldn't even gig that much really. It wasn't like getting picked up by one of those American, touring older guys that just tour for a year and you learn everything for however long. ${ }^{22}$

What is interesting is that Downes reflects elements of both King's and Carr's comments by suggesting that both performing with a 'master' as well as extensive touring are integral to successful engagement with jazz. King's comment hints at the fact that - at least in the earlier days of British jazz - being separated from American musicians meant being prevented from interacting with a community of elders that would consequently engender a feeling of ownership and belonging. Carr suggests that the problem is more to do with a lack of an infrastructure that would provide the opportunity for increased performance experience, and thus greater mastery of the idiom.

Taking into account all of the above, we can see several possible factors that contribute to the 'American question'. At least in the early days of jazz in Britain, there were legitimate concerns about authenticity and ownership. The first generation of British jazz musicians might well have doubted their credentials, due, at least in part, to their relative lack of a tangible tradition with which to identify. Furthermore, geographical separation from both the lineage of masters and the potentially more accommodating infrastructure in the US were major reasons for this doubt. 
However, this state of affairs has not endured. During the ensuing years the logistical barriers between British and American musicians were gradually removed. Once the MU ban was lifted completely then visiting Americans became a regular feature of the London jazz scene, in particular in Ronnie Scott's club, where the house rhythm section - including Tony Levin - would play with many soloists from the US:

Olie Brice: [Levin did] play jazz every night for decades with the finest of players, so he had that experience of doing weeks with Joe Henderson, Ben Webster, Coleman Hawkins. Not to mention Art Themen, Stan Tracey [...] So he had some access that's just rare to anybody. ${ }^{23}$

From these initial encounters, personal friendships developed between British and American musicians, and often resulted in them making records together. ${ }^{24}$ This shows us that, within even a few short years of the period described by King, the UK jazz scene had begun to locate its masters and consequently, to shrug off feelings of inauthenticity or inferiority.

\section{Today}

So far I have been looking at the historical and theoretical context of some of the questions that face contemporary British jazz musicians. We have seen that in recent times the rise of the American-centric reading of jazz history has created certain divisions between American and non-American practitioners and commentators and in addition, historically, the issues of authenticity and ownership were bound up with legitimate questions of community, geography and nationality. I will now bring the argument into the present by questioning the extent to which these issues remain relevant among musicians and, as a result, the effect this has on the ways they locate their practice in relation to the historical jazz tradition.

\section{Records}


We have already seen that for previous generations, access to jazz was largely restricted to recordings and that the chance to see American musicians performing live was a rare occurrence. This is an experience that, albeit for different reasons, is also evident among modern musicians during their formative years. Although the specific artists heard vary from person to person, a recurring theme is early exposure to mainstream American jazz:

Corey Mwamba: My folks listen to Bing Crosby and Louis Armstrong and Nat King Cole... And, of course, Humphrey Lyttleton's show, which I used to tape religiously and listen to later. ${ }^{25}$

Downes: That kind of music [American mainstream] is what got me into jazz in the first place. So things like Oscar Peterson, Bud Powell and all those old greats. $^{26}$

My own background followed a very similar pattern. As I have already discussed, extensive listening is one effective way of internalising the sound of the idiom. However, although a valuable source of purely musical information, accessing jazz via these means can also create certain barriers to forming a personal connection with the idiom:

Kinch: Whilst I held John Coltrane and that music in such high esteem - and especially Art Blakey and the pan-Africanism of Max Roach because that spoke to me at one level - it also felt unattainable [...] I think a lot of what we're dealing with is a cultural baggage that's inherited about jazz being opaque, it being maybe too heavy for the common folk to understand. And then people become deified. So John Coltrane you don't identify with even as someone in your direct lineage irrespective of your colour or background because they're canonised. They're in these rarefied canon environments and you're never going to quite play that well. ${ }^{27}$ 
Here Kinch describes the inherent difficulty of identifying with certain historical figures. In terms of the discussion of nationality, this is not necessarily a phenomenon unique to the UK, as I imagine a young saxophonist listening to a John Coltrane record in the US would experience a similar feeling of unattainability. However, with respect to the way musicians connect with the tradition, it bears certain relevance to my discussion.

Yet another catalyst for feelings of disconnection can be found in the following quote from Downes, the recognition of which might help us to contextualise the feelings expressed by Peter King.

Downes: When I first discovered it [jazz], it was like being a voyeur into it, being obsessed in this little world that doesn’t exist any more somehow. You know, like tracing music back to some exciting past and having this visualisation of what it was like in Harlem. That, as a kid, is the special place that jazz occupied in my head. ${ }^{28}$

These comments reveal that, as well as being a partial result of historical distance, feelings of separation are also the consequence of immersive listening to recorded music without any human interaction - Downes' comparison to voyeurism I think is particularly interesting in this respect. That is not to say that listening is not an important part of learning jazz (I would certainly argue this as a result of my own early experiences). Nevertheless, it needs to be balanced by other activities. ${ }^{29}$ Rachel Musson makes an interesting point when reflecting on her own lack of such a formative immersion:

I feel that [listening to records] is a far more authentic way to come to the music... and the way I came is slightly more fraudulent. ${ }^{30}$

The implication is that listening to records - and the resultant familiarity with the idiom - is in some way connected to authenticity and so, for Musson, coming to jazz as a performer without already having a knowledge of the music is apparently detrimental to one's engagement with the idiom. What we are beginning to see from these comments is a sense 
that involvement with aspects of the tradition are an important step on the path to becoming a jazz musician, but that there also other elements that need to be addressed.

\section{History}

Having touched upon some of the factors that can potentially cause a feeling of disconnection with the jazz tradition, I was then interested to find out how these musicians went about finding a resolution. I began by questioning what they understood the tradition to be, both in musical and cultural terms. Taking into account the non-American status of my interview subjects, it is not necessarily surprising to find that the diverse cultural history of jazz was soon on the agenda:

Alexander Hawkins: The music was a creole when it started. For sure there are the American art forms in there such as the blues, such as gospel music, but then, even taking those....as the two arch examples, you can't really understand the blues without understanding West African music, you can't understand gospel music without understanding Scottish Methodist music and the way that migrated in previous centuries. So to ignore the creole aspect of the early jazz is to ignore Caribbean influences, Sufi devotional influences, European classical influences. And so, for me, jazz is inherently this creole music, so therefore you shouldn't really be surprised that nowadays it finds manifestations in all sorts of other places. ${ }^{31}$

Here we see Hawkins highlighting the multi-cultural origins of jazz as a way of deconstructing the American-centric reading of jazz history and thus offering a potential legitimacy for non-American practitioners of any cultural origin.

Others identified more direct links to their personal circumstances: 
Brice: There's a really brilliant book [...] by Nat Hentoff called Hear Me Talkin' To Ya, [which is] really interesting in that [sense] [...] I was very interested to discover that Willie 'The Lion' Smith was Jewish, and he talked bilingual Yiddish [...] Things very quickly become determined as something that they weren't. The example I often give is that people would say I'm white, but that wouldn't be my grandparent's experience, although they had the same skin colour as me. Jews [of their generation] wouldn't have been seen as white in England [...] I think all of that history is much more complex and varied than the history told by Ken Burns and Wynton would suggest. Which isn't in any way to seek to underplay the black experience in America and the relevance of slavery to jazz etc. But it was always a music that was diverse in its influence and was about a very complicated, mixed and unsettled community. $^{32}$

Kinch: [...] then there's all sorts of overlaps. One actually, a weird one, was meeting Wessell Anderson [...] [and] talking about my background in New York and my aunt Joyce and recognising that he's Bajan as well and his mom is almost a mirror image of my cousins in New York. And my perception from afar is that he must come from hundreds of years of New Orleans Alvin Batiste students [whereas he] is actually from West Indian parentage, grew up in New York and got into the music. ${ }^{33}$

There is an emerging paradigm in jazz studies that calls for a re-reading of the origins of the music that better accounts for the cultural complexities found therein. Although much of this scholarship focuses on historical and theoretical aspects, the above series of comments shows the value of such thinking with respect to understanding the work of contemporary musicians. By identifying the complex cultural background of two ostensibly 'thorough-bred' American musicians - one a Harlem stride pianist, the other a one-time lead alto saxophonist 
in the Lincoln Center jazz orchestra - Brice and Kinch not only identify cultural links to their own particular circumstances, but taken in more general terms, they reveal the inherent instability of such a restrictive perception of history. In fact, Kinch refers directly to his preconception that Anderson must be the product of a long line of New Orleans musicians and to his resulting surprise when discovering the reality to be slightly more complex. As Hawkins says: 'if you try to unpick the idea of authenticity, [it] really doesn't hold.'34 While speculating as to possible reasons for these preconceptions of authenticity, Kinch drew on his experience as a hip-hop artist:

It leads me on to another thought about genre and tradition. America is a genius at the invention and promulgation and propagation of genres. [In the case of hip-hop], people have been rapping since before any recording equipment ever existed, it's well steeped in the creole traditions of Mali and the West Indies. You've got [West Indian] toastin' traditions. But somebody came along in the late 70 s and said: "Right. This version of partying that you've done as Africans for millennia, we're gonna package it, box it, capitalise on it, commodify it and make a killing out of it." That's what the hip-hop industry has become. If you look at the tradition, though, it goes back much, much longer than that, and it's far less culturally exclusive. All of the assumptions about what it means to be a hip-hop artist, if you're in the commercial genre world of it, are vastly different than if you're in the tradition. If you're in the tradition, and you can spit, or you can spin on your head, whatever the tradition requires from hip-hop culture, you're valid. Whereas, if you're in the commercial zone and you've not got a beard, you've not spent time in jail and you've not sold crack and you're not black and from the 'hood, suddenly these questions of validation have more weight. It's true in jazz as well. We're just looking down a longer lens at what's happened, but 
those same assumptions will trouble jazz at a certain point. This is a commercial entity versus a tradition that African people have done in contact with European culture for a very long time..$^{35}$

Nevertheless, despite obviously being well aware of the inherent complexities of jazz's cultural origins and the instability of too myopic a reading of history, it is also clear that modern British musicians are both knowledgeable and respectful of the American tradition. Of course, the extent to which each individual engages with it is variable, but during my conversations I noted a common desire to explicitly acknowledge the importance of that tradition, and in most cases, to be recognised as a part of it:

Mwamba: You know what? Yeah, yeah, I do [self-identify as a jazz musician]! And do you know why? Because I can do it! I've been to New York. I played piano in New York with Patience Higgins [...] I played on the day Kenny Kirkland died, that's when I was there [...] Someone took a picture of me in St. Nick's in Harlem playing piano, some bassist in the corner. I played 'Angel Eyes'. They asked me to stay for weeks. I'm happy to say that I'm a jazz musician. Just for the simple fact that that is where I am from. That gives me an identity. I'm not an American. I'm not an American jazz musician. I'm a British jazz musician. But I'm a jazz musician. ${ }^{36}$

Brice: If I had to pick one description of what I am I'd say I'm a jazz musician, although I'm aware that's not an uncomplicated assertion. But broadly I totally see what I do as in that tradition [...] [although] there's obviously all kinds of issues around jazz being black and American and I'm neither of those. ${ }^{37}$

Clearly there is still a strong identification with the jazz tradition among musicians who, at least objectively speaking, have little apparent connection with it - 'being a white, reasonably 
middle class piano player from Norfolk feels a million miles away from the origin of that music'.38

Not all of my interviewees were quite so unequivocal in identifying as jazz musicians per se, but even taking this into account, the influence of jazz as a contributing factor was explicitly acknowledged:

Musson: I think [jazz is] part of what I do in that it's very deep in my language and the way I express myself, but at the moment I choose not to play conventional standard jazz harmony or form or rhythm. I play outside of all those things, so there are elements of the tradition that are in my language but I'm now playing a kind of music that's formless. ${ }^{39}$

Overall, what we see is a demographic whose knowledge and understanding of the musical and cultural context of jazz has resulted in an awareness of the potential issues surrounding self-identification. Inevitably, each individual has a different interpretation of their role in the greater scheme of things, but what is clear is that they have all spent time contemplating the implications of these issues and ways to resolve them.

\section{Community}

We have considered how early exposure to jazz via recordings from the American mainstream tradition can, in some cases, lead to a feeling of alienation. Therefore, aspiring British musicians are soon faced with the challenge of making the music of the 'exciting past' relevant to their own social and cultural conditions. Kinch explained how meeting and interacting with local musicians can help to identify a clearer pathway into the music:

I could probably point to meeting Jason Yarde at Midland Arts Centre when I was going to those jam sessions way back in the day as a moment of like 'Oh, he's 23, he's playing the saxophone REALLY well, his 'Caravan' sounds as good as Wynton's, it's amazing.' He's playing the hell out of the saxophone, 
and yet he's approachable, affable, or somebody who, in terms of background, in terms of culture, I could easily identify with and it made me feel like 'Ok, yeah. I can do that.' I remember having that chat with Andrew McCormack years later and he was saying the same thing. For him, meeting Jason Rebello was a real epiphanal, watershed moment. That's like 'Yeah, Kenny Kirkland I dig all that. McCoy, that stuff's what I'm into.' But, until you've met somebody that you can identify with culturally, playing at that level, it felt like a barrier you'd never be able to attain. ${ }^{40}$

These comments demonstrate the value of joining a community of like-minded peers as a valuable step towards connecting with jazz. For a young musician who might feel that the weight of history makes it 'unattainable' or 'too heavy' for them to interact with, an encounter with musicians from a similar social background can offer a way of bridging the cultural and historical gaps between themselves and the tradition.

Of course, it is not always the case that hearing jazz on record precedes hearing it live, or even performing it. In some cases, a musician might come to jazz having no prior knowledge or expectations:

Musson: I was playing flute at school, and a little bit of saxophone, and I saw a advert for the Glamorgan summer school, which was in my home town of Porthcawl, and I went on that, not really knowing what it was all about [...] It completely changed my life $!^{41}$

In this case, the weight of cultural baggage imposed by a familiarity with the history is absent and so the novice might well be much freer to respond to the music in a more spontaneous manner. However - as Musson reveals - this approach is not free of perceived problems either. It is interesting to note that she felt that coming to jazz without any prior listening experience was somehow a less authentic route in. While I would argue that there is no 'correct' way to discover jazz (and that, if anything, coming into contact with the music first- 
hand might be a more 'authentic' way if we accept that music-making is primarily a social activity), her subsequent comments help to clarify her position:

I feel that's a far more authentic way to come to the music... and the way I came is slightly more fraudulent [...] Part of the reason [that I think this] is that I teach, and I teach a lot of adults, and some of those adults never listen to any music, never go to any gigs, but any free time they've got they'll go to a jam session. The whole of their jazz education is based on either coming to my classes or what they hear at a jam. I can't bear that idea because I think it's really disconnected from tradition. ${ }^{42}$

Here Musson hints at the fact that, on its own, jam session attendance is not sufficient for complete immersion, and that knowledge of historical musical practices is also required much in the same way that prolonged listening without interaction with a community can have the same result in reverse. I would argue that this is what Kinch means when he says 'jazz is an identifiable tradition, not just a genre' - that as well as being based on a combination of performance practices, jazz is also a lineage that requires an appreciation and knowledge of both its musical and cultural history. I believe this relates to what is known as 'paying dues', and is an essential part of the jazz learning process. ${ }^{43}$ Berliner described this as a process that "places its emphasis on learning rather than teaching, shifting to students the responsibility for determining what they need to learn $[\ldots]$ and from whom' ${ }^{44}$ What this suggests is that, in addition to both listening to records and playing with friends and contemporaries, interaction with older musicians is a third important stage in the development of jazz musicians:

Brice: People talk about how the apprentice thing in jazz is a thing of the past, but in my experience that has totally been the important experience of my learning to play, and much more than any institutionalised educational setting. And so playing a lot with Tony [Marsh], playing a lot with Mark [Sanders], 
playing a lot with Jeff [Williams], that's where it comes from more than anything else..$^{45}$

Kinch: $[\ldots]$ meeting Courtney Pine and Steve Williamson as a teenager and Courtney saying "You can play. You're going to be even better. Here's a mouthpiece. Come round the house, let's listen to some records.” And I'm 17 years old. Being brought into that fraternity was a thing of "I see what your aspirations are. I can help you to get there."46

This idea leads me back to one that I touched on earlier. In my comments about the possible reasons for King's generation requiring external validation of their activity, I speculated that one might have been the lack of such a community of elders. The following anecdote, recounted by one of my interview subjects, sheds some further light on this phenomenon and gives more weight to the argument that authenticity - in this case phrased as the 'real thing' is bound up with ideas of tradition and community:

I went to part of the UK where there's not very much [...] going on at all and played with someone who felt that, in order to play, he didn't have anyone to draw on, so he had to bring people over. [Someone asked him] "why don't you just get some people together and do some improvising? In London everyone just gets together and has a play. They don't worry about it." Whereas there was this sense of having to have the "real thing" that he'd only seen on the web or listened to on records. Then when we went away again, there was a sense of the music leaving his world again. That just felt really odd, and I couldn't work out if it was just him and his perception of his surrounding scene, or if there really was that going on.

What these comments reveal is that, for the musician in question, there was a feeling of not being connected to a recognised community of musicians, and that this was somehow restrictive of their ability to engage with the music. I would argue that what might have put 
him off 'getting some people together and playing' would have been the absence of a connection to the tradition, and that this could well have motivated his desire for the 'real thing', which could be interpreted as more experienced musicians who have already 'paid their dues'.

This sentiment resonates with King's comments about the early years of the modern jazz scene in the UK. Both 1950s Britain and the unnamed location above appear to have lacked the community of elders that would have lent them credibility. What is interesting to me is that above we find Brice and Kinch naming a series of British musicians - Marsh, Sanders, Pine and Williamson - in just such terms. The implication is that, according to the younger two musicians, there is now an undoubted lineage of British elders. In addition to this, I would personally cite Peter King himself as one of the major figures in the history of British jazz, and my experiences of performing with him as being among the most formative of my early career. This clearly indicates that the ensuing years have allowed for the evolution of a distinct British jazz lineage.

Returning to the theme of geographical location, Corey Mwamba took an interesting perspective:

I do have a problem with people that reject the local as inferior, and only think that the root is important when they are nowhere near the root. Because this wouldn't exist without the root and they wouldn't exist without the local. And so once you start divorcing yourself from the local, then actually, you don't have that real connection with the root. It's like saying that[...] [it] is connected to the tree itself even though it's cut off. That's nonsense, it's not. If it's cut off, it's not connected. ${ }^{47}$

We have seen that, for most musicians, acknowledgement and respect for tradition is essential, but Mwamba's words remind us to pay similar respect to the local. I would suggest that here lies one of the most fundamental issues facing the British jazz musician (or any non- 
American jazz musician for that matter). The question is how to find a balance between the historical and local. He went on to make an interesting point about a certain type of neoconservative musician that he believes has not found this balance:

If you think about 2015 in London and you think about the music that these people are playing, and why they're playing that music, who they're playing that music to $[\ldots]$ It's culturally inappropriate. ${ }^{48}$

It is clear that a key aspect of this process is finding a satisfactory balance of numerous factors. During more than one conversation, I found that my interlocutor adopted a critical stance in response to a failure to balance these elements. For example, Mwamba's use of the term 'culturally inappropriate' clearly shows that he considers the cultural context of one's music-making to be of equal importance as the musical.

Hawkins - in an email exchange subsequent to our initial conversation - took up the concept of 'paying dues' as another potentially problematic area:

'Paying dues' for me is an idea too bound-up in various normative narratives...e.g. that you 'have' to be able to cut it in a jam session setting (in which a certain set of technical facilities are 'required', and where you 'have' to know a bunch of tunes, and there are certain expectations that you can 'deal' with levels of technical complexity, etc; and then the problematic layers of competition and domination these ideas hint at) Although I understand that these skills can be useful to the musician, I'd definitely reject the idea that the jam session experience is in any way necessary. And a 'due' is a 'debt', which is something that has to be paid. No-one (for me) has to pay a price to exercise creativity. ${ }^{49}$

Kinch also acknowledged the importance of balancing the local with the historical: 
I think it's another false dichotomy to an extent, though, because the latent assumption [is] that if you do embrace the tradition and the social or historical aspect...it...somehow makes your own connection to the music less pure, more culturally biased. Whereas I think it's always been possible for people to have a healthy respect and regard for the tradition, the heritage, the socialpolitical circumstances that forge the music, whilst not being directly of that experience. And how else would you find your own relevance within it? ${ }^{50}$ What is evident is that, for jazz musicians of any nationality, there are a number of factors that In the case of jazz in America, the distinction between the historical and local is much less clear, and any that does exist is not made on national grounds. For British musicians, on the other hand, the American history is augmented by a second, national history - one that, for both cultural and logistical reasons, can be much easier to access. This is a feeling that was expressed by Brice:

I think that is part of the attraction to me of the freer stuff. I feel that I've really thrown myself into the lineage - a younger lineage - of London free music. I've gone out of my way to see the stuff I really care about a lot. I couldn't begin to count the number of times I've seen Evan Parker for example. It must be more than thirty times certainly. And getting to experience that in a small club regularly is amazing, and I think that is probably the closest available thing to us to going to see Coltrane, in terms of seeing truly amazing, creative improviser at the height of his powers, close up, feeling what it's like in a small room. ${ }^{51}$ 
Brice's identification of a distinct lineage - improvised music in this case - leads me on to the question of how contemporary British musicians relate to the history and tradition of jazz in the UK. There are already books ${ }^{52}$ that lay out the historical details of jazz in Britain and, as a result, I do not intend to cover this ground again here. Instead, I will consider the performers that my interviewees consider to be the most influential and question what aspects of their work are seen as being so significant.

I have already commented on the fact that my interviewees had referenced certain key musicians when discussing formative performance experience, and that this fact is indicative of an emerging historical lineage in the UK. It quickly became apparent that each of my subjects had a set of criteria for identifying significant musical figures, and that this was based as much as anything on the perceived success these figures had achieved in finding a voice that respected the jazz tradition, but was not overly beholden to it:

Downes: Those early things stay with you so strongly. They become almost their own thing. It doesn't matter what period it's from. But then, after that, when I wanted to progress what I was doing, the things that I was finding around me at that time - people like Julian [Arguelles] and Loose Tubes - felt a lot more relevant.... they were also a scene of musicians that felt musically a little bit closer to what I was into than the older generation in Britain, above them, which felt more American-centric. ${ }^{53}$

Brice: I do feel a more exciting lineage in London has been a more left-field one, I find Paul Dunmall and Evan Parker certainly more individually significant. Yeah, they excite me more. I guess part of what is exciting is people creating their own music and really having their own thing. ${ }^{54}$

Downes and Brice reference two separate stylistic sub-strata that have emerged in the UK. Although ostensibly quite different, what both have in common is the fact that, in the eyes of these modern musicians, those who were involved in creating these styles have been more 
successful than previous generations in solving the problem of balancing respect for the jazz tradition with their own social and cultural backgrounds. This is also a trait that is valued when observed among colleagues and contemporaries:

Mwamba: You know when I listen to, whose name can I think of now? Shit, when I listen to Chris Sharkey, for example, I can hear him drawing [...] from an American root, I can hear the Downtown scene in him, but then I can also hear this rock and all that stew that he creates within that and [as a result] his music is entirely authentic.

\section{Conclusion}

During this extremely brief survey, I have considered the way that contemporary jazz musicians in the UK view themselves in relation to the historical jazz tradition and questioned what are the factors that relate to their own musical identity. We have seen how the apparent dichotomy between American and European jazz can be resolved by an understanding of both the historical origins of the music as well as the musical and social practices of this tradition, and how, by applying these practices to their own circumstances, British musicians are able to contribute their own voices to the ever expanding tradition of jazz. While the performers I have interviewed for this chapter work in variety of different stylistic areas of the music, what they have in common is the understanding that in order to engage successfully and meaningfully with this music in its broadest terms, one must aim to attain this balance. One more thing that I hope this chapter has revealed is the value to jazz scholarship of practicing musicians, not only as sources of primary-source research material, but also as thinkers. Many of the theoretical issues that are tackled by scholars are ones that confront practitioners on a daily basis. As Kinch points out: 'I've thought long and hard, and reflected on what's your conduit, what's your entry point to the lineage, how you 
contextualise yourself and your story within it. ${ }^{55}$ This is a task that faces all creative musicians who want to do more than simply mimic the voices of others.

At the beginning of this chapter I indicated that Carr's book had been a source of inspiration for the present work. If we now compare the situation that Carr's generation were in at the start of the 1970s with present conditions for musicians in the UK, we see both similarities and differences. For example, although the nature of the discourse had undoubtedly changed, the 'American question' still persists. I would argue that, although it is no longer quite such a 'romantic' view, the issue remains and consequently now, as then, creative musicians call for their work to be judged on its own terms rather than a set of criteria imposed via a subjective historical interpretation.

That is not to say that musicians operate in a vacuum, and all of my interviewees identified the importance of community and tradition in their work. One of the key aspects of the UK jazz scene in the twenty-first century is, thanks to the commitment to the aforementioned ideals on the part of previous generations, an ever-expanding historical lineage of British jazz elders. This was clearly something that was lacking in the early days of jazz in the UK, and I think it would be valuable to note that many of the musicians who expressed doubts as to their authenticity in their youth are now considered to be major figures in the history of their music. I believe this reveals an important interaction between individual and community, and is indicative of the inseparability of the two.

To sum up, we might say that the task of the twenty-first century British jazz musician is to assimilate the musical and cultural histories of jazz in all its guises before finding a way of utilising this body of knowledge to represent their personal cultural, social and creative situation in music. Unfortunately, limited space has prevented me from including more extracts from the many hours of enjoyable and enlightening conversations that I undertook in preparing for this chapter. By way of making amends, I will conclude with some final thoughts from the musicians themselves: 
Downes: If you're involved in the arts in any way, I think you are defined by how gracefully you can leap between the academic obstacles throughout your career, without getting stuck in them but still being able to learn from them and get things from them. I think that defines your path. Staying relevant and contemporary and interesting but still managing to be supported and educated..$^{56}$

Musson: I suppose because the tradition has given us stepping-on points you're not trying to reinvent the wheel each time. It's like something that has developed and you are just dipping into it. When you feel like you have enough of it down [...] you are able to start doing your thing. ${ }^{57}$

Brice: You can't be what you're not, but if you do the spirit of what people did rather than the specifics of what they did, using the things available to you and trying to have your own personal spin, that whole pool of stuff's there for you. ${ }^{58}$

Kinch: Our past is almost immaterial. It's what's your proficiency with the language or what's your awareness of the language's history that enable you to converse with people. ${ }^{59}$

Mwamba: I think the tradition of jazz is that it's a music that allows you to be you. It's not a music that allows you to be somebody else. And if you want to 
be somebody else then you could play any music that you liked. But if you want to be you, play jazz. ${ }^{60}$

\section{Bibliography}

Atkins, E. Taylor, Jazz Planet (Jackson: University Press of Mississippi, 2003).

Berliner, Paul, Thinking In Jazz: The Infinite Art of Improvisation (Chicago: University of Chicago Press, 1994).

Brice, Olie, Conversation with the author, 2015.

Carr, Ian, Music Outside: Contemporary Jazz in Britain (London: Northway Publications, 2008).

Clark, Kenny and Boland, Francy, Sax No End (SABA LP, 1967).

Collier, Graham, The Jazz Composer: Moving Music Off the Paper (London: Northway Publications, 2009).

Downes, Kit, Conversation with the author, 2015.

Gebhardt, Nicholas, "When Jazz Was Foreign: Rethinking Jazz History.” Jazzforschung Volume 44, 2012: 185-198.

Gelly, Dave, An Unholy Row: Jazz in Britain and its Audience 1945-1960 (Sheffield:

Equinox, 2014).

Gonzalves, Paul, Hummingbird (Deram LP, 1970).

Hawkins, Alexander, Conversation with the author, 2015.

Hayes, Tubby, Return Visit (Fontana LP, 1962).

Heining, Duncan, Trad Dads, Dirty Boppers and Free Fusioneers: British Jazz 1960-1975 (Sheffield: Equinox, 2012).

Iverson, Ethan (2010) http://dothemath.typepad.com/dtm/wynton-marsalis-readers-

guide.html Accessed on 20/11/2015 
Iverson, Ethan (2015) http://dothemath.typepad.com/dtm/interview-with-nicholas-

payton.html Accessed on 20/11/2015

Kinch, Soweto, Conversation with the author, 2015.

King, Peter, Jazz Britannia - Episode 2 BBC Four, 2005.

Marsalis, Branford (2010) https://vimeo.com/36469783 Accessed on 20/11/2015

Monson, Ingrid, Saying Something: Jazz Improvisation and Interaction (Chicago: University of Chicago Press, 1996).

Moore, Hilary, Inside British Jazz (Farnham: Ashgate, 2007).

Musson, Rachel, Conversation with the author, 2015.

Mwamba, Corey, Conversation with the author, 2015.

Nicholson, Stuart, Is Jazz Dead, Or Has It Moved To A New Address? (New York:

Routledge, 2005).

Titon, Jeff, Early Downhome Blues (Chapel Hill: University of North Carolina Press, 1994).

Toynbee, Jason, "Race, history, and black British jazz." Black Music Research Journal,

Volume 33, Number 1 (Spring 2013), 1-25.

Toynbee, Jason, Tackley, Catherine and Doffman, Mark, Black British Jazz: Routes,

Ownership and Performance (Farnham: Ashgate, 2014).

Vitali, Luca (2014) http://musicnorway.no/2014/07/14/sound-check-norway-music-fromnorway-why-it-was-so-important-to-write-a-book-about-it/Accessed on 20/11/2015

\footnotetext{
${ }^{1}$ Atkins, E. Taylor, Jazz Planet (Jackson: University Press of Mississippi, 2003), xvi.

${ }^{2}$ Berliner, Paul, Thinking In Jazz: The Infinite Art of Improvisation (Chicago: University of Chicago

Press,1994); Monson, Ingrid, Saying Something: Jazz Improvisation and Interaction (Chicago: University of Chicago Press, 1996).

${ }^{3}$ Toynbee, Jason, Tackley, Catherine and Doffman, Mark, Black British Jazz: Routes, Ownership and Performance (Farnham: Ashgate, 2014).

${ }^{4}$ Carr, Ian, Music Outside: Contemporary Jazz in Britain (London: Northway Publications, 2008).
} 
${ }^{5}$ Trachtenberg in Titon, Jeff, Early Downhome Blues (Chapel Hill: University of North Carolina Press, 1994), xii.

${ }^{6}$ Branford Marsalis quoted in Collier, Graham, The Jazz Composer: Moving Music Off the Paper (London: Northway Publications, 2009).

${ }^{7}$ Atkins, Jazz Planet, xi.

${ }^{8}$ For readers in search of more on this expansive debate, I'd recommend as a starting point Ethan Iverson's series on Marsalis on his Do The Math blog (2010) and, for a summary of the counter-arguments, Nicholson's chapter 'The Wynton Marsalis Phenomenon' (2005)

${ }^{9}$ Nicholas Gebhardt, "When Jazz Was Foreign: Rethinking Jazz History.” Jazzforschung Volume 44, 2012: ??. As much as Marsalis' name has become synonymous with the neo-classical stance, I think it is important to acknowledge that his views are often oversimplified or taken out of context - especially in the America versus Europe debate. Therefore, in the interest of a balanced argument, I include the following comment made by Soweto Kinch during our conversation. 'Listen to the way that Wynton and the cats deify Joe Temperly. "He's the authentic voice of the lineage and the tradition" and he's Scottish. So there's a point at which connecting with the language and the tradition supercedes national things as well.' Kinch (2015)

${ }^{10}$ An unfortunate side effect of this debate is increasing evidence of what might be described as 'factionalism'. This can, on one hand, lead such a prominent American musician as Branford Marsalis to say of European jazz musicians that 'as long as I don't sound like them, I have no problems' (Marsalis, 2010) and, on the other hand, make European writers feel the need to contemplate, for example, Norwegian jazz's role in 'emancipating European jazz from its Afro-American roots' (Vitali, 2014) Whether Vitali's use of such historically and culturally insensitive terminology is deliberately provocative or simply the result of incredible naiveté, it is hard to see how such rhetoric can be anything other than divisive.

${ }^{11}$ Carr, Music Outside, 139.

${ }^{12}$ King, Peter, Jazz Britannia - Episode 2 BBC Four, 2005.

13 Iverson, Ethan (2015) http://dothemath.typepad.com/dtm/interview-with-nicholas-payton.html Accessed on $20 / 11 / 2015$

${ }^{14}$ Kinch, Soweto, Conversation with the author, 2015.

${ }^{15}$ Ibid.

${ }^{16}$ Berliner, Thinking in Jazz, 37.

${ }^{17}$ Harriott quoted in Toynbee, Jason, "Race, history, and black British jazz." Black Music Research Journal, Volume 33, Number 1 (Spring 2013), ??

${ }^{18}$ Ibid., ?? 
${ }^{19}$ Kinch, Conversation with the author, 2015. I interpret Kinch's comments as referring to the belief that a firsthand knowledge of rules and customs are prerequisite for 'authentic' participation.

${ }^{20}$ Of course, it is impossible to have any discussion of jazz without acknowledging the significant impact of the race issue, but further consideration would be beyond the remit of this article. For a much more comprehensive exploration of the subject of race in British jazz I direct the reader to Moore, Hilary, Inside British Jazz (Farnham: Ashgate, 2007) and Toynbee et al., Black British Jazz.

${ }^{21}$ Carr, Music Outside, 139.

${ }^{22}$ Downes, Kit, Conversation with the author, 2015.

${ }^{23}$ Brice, Olie, Conversation with the author, 2015.

${ }^{24}$ Hayes, Tubby, Return Visit (Fontana LP, 1962); Clark, Kenny and Boland, Francy, Sax No End (SABA LP, 1967); Gonzalves, Paul, Hummingbird (Deram LP, 1970).

${ }^{25}$ Mwamba, Corey, Conversation with the author, 2015.

${ }^{26}$ Downes, Conversation with the author, 2015.

${ }^{27}$ Kinch, Conversation with the author, 2015.

${ }^{28}$ Downes, Conversation with the author, 2015.

${ }^{29}$ It should also be noted here that historical recordings are, of course, not the only medium by which a young musician can discover jazz - a point that I will return to later.

${ }^{30}$ Musson, Rachel, Conversation with the author, 2015.

${ }^{31}$ Hawkins, Alexander, Conversation with the author, 2015.

32 Brice, Conversation with the author, 2015.

${ }^{33}$ Kinch, Conversation with the author, 2015.

34 The fact that Hawkins and Kinch both reference the connections between the Caribbean and jazz forges a strong link to Gebhardt's study of early jazz via Lomax's recorded interviews with Jelly Roll Morton.

${ }^{35}$ Kinch, Conversation with the author, 2015.

${ }^{36}$ Mwamba, Conversation with the author, 2015.

${ }^{37}$ Brice, Conversation with the author, 2015.

${ }^{38}$ Downes, Conversation with the author, 2015.

${ }^{39}$ Musson, Conversation with the author, 2015.

${ }^{40}$ Kinch, Conversation with the author, 2015.

${ }^{41}$ Musson, Conversation with the author, 2015.

42 Ibid.

${ }^{43}$ Musson made another comment here, which I interpret as being bound up with the paying of dues:

'Something that I find attractive in any form of music, but particularly in jazz and improv, is the amount of work involved.'

${ }^{44}$ Berliner, Thinking in Jazz, 51.

${ }^{45}$ Brice, Conversation with the author, 2015.

${ }^{46}$ Kinch, Conversation with the author, 2015.

${ }^{47}$ Mwamba, Conversation with the author, 2015. 
${ }^{48}$ Ibid.

${ }^{49}$ Hawkins email.

${ }^{50}$ Ibid.

${ }^{51}$ Brice, Conversation with the author, 2015.

${ }^{52}$ Moore, Inside British Jazz; Heining, Duncan, Trad Dads, Dirty Boppers and Free Fusioneers: British Jazz 1960-1975 (Sheffield: Equinox, 2012); Gelly, Dave, An Unholy Row: Jazz in Britain and its Audience 19451960 (Sheffield: Equinox, 2014).

${ }^{53}$ Downes, Conversation with the author, 2015.

${ }^{54}$ Brice, Conversation with the author, 2015.

${ }^{55}$ Kinch, Conversation with the author, 2015.

${ }^{56}$ Downes, Conversation with the author, 2015.

${ }^{57}$ Musson, Conversation with the author, 2015.

${ }^{58}$ Brice, Conversation with the author, 2015.

${ }^{59}$ Kinch, Conversation with the author, 2015.

${ }^{60}$ Mwamba, Conversation with the author, 2015. 